\title{
RESEARCH ON PURPOSE OF DETERMINING THE OPTIMAL CONFIGURATION OF BLADES FOR IMPROVING THE ENERGY EFFICIENCY OF DIRECT FLOW HYDRO TURBINE
}

\author{
Dinara TURALINA ${ }^{1}$, Gauhar KAZAKBAY ${ }^{* 2}$ \\ ${ }^{1,2}$ Kazakh National University named after Al-Farabi, Dept. of mechanics, \\ Al-Farabi 71, Almaty, Kazakhstan \\ *gauharkb@mail.ru
}

Received: 8 February 2018; Accepted: 30 April 2018

In this paper we present the results of the research conducted to determine the effective variant of guide vane and hydro wheel blades of direct flow hydro turbine. The aim of the theoretical study is to determine the optimal configuration of hydro turbine blades to improve the energy efficiency of the hydro turbine. As a result of the theoretical study, a mathematical model of a hydro turbine was developed in the interactive COMSOL Multiphysics. With the help of the COMSOL Multiphysics application program, the change in velocity and pressure distribution of water through the guide vanes and hydro turbine blades the optimal shape and angle of the guide device and the hydro wheel blades of the hydro turbine were determined. Based on the results of the research, it was determined the optimal configurations of the hydro wheel blades with high energy efficiency.

Key words: hydro turbine, hydro wheel, blade, COMSOL Multiphysics, energy efficiency, guide vane. .

\section{Introduction}

Today, the whole world pays great attention to water flow energy as the effective source of energy. However, hydropower engineering is a complex architectural and engineering issue. For example, build the dam is a very complex construction, and it occupies a very large area, has a negative effect on the life of aquifers, when water accumulates in the dam, if there is a problem with the dam, can cause a serious catastrophe, may be dangerous to the environment. Investigated hydro turbine for small hydroelectric power station does not require a dam, therefore, eliminates the above mentioned shortcomings. There are no shortcomings mentioned above. Instead, it works in scheme as a part of the water given to head tube, after flowing through hydro turbine again dumped into the river. This direct flow hydro turbine's size is small, so to construct it needs less material accordingly it costs cheaper.

It is significant to correctly choosing of the structure of the turbine, the size and location of the blades, the parameters of the guide vane, the head of water, the structure of the hydro wheels when installing a hydro turbine on a water stream to generating sufficient energy and effective working. Scientific research working is aimed to improving low head hydro turbine efficiency by changing the stream flow to hydro wheel. The optimal version of the attack angle on guide vane and hydro wheel blades is for improving efficiency of hydro turbine. Investigated low head hydro turbine can be used in the small and medium rivers of the Central Asian countries and Kazakhstan. This low head hydro 
turbine for small hydroelectric power station is for using for seasonal agriculture to farmers and for using in small settlements and remote villages [1-6].

\section{Methodology}

The method of investigation is a computational experiment. A theoretical study was carried out, a mathematical model of a hydro turbine was developed in the interactive COMSOL Multiphysics. By COMSOL Multiphysics application program, the change in velocity and pressure distribution of water through the guide vanes and hydro turbine blades. For the manufacture of a hydro turbine, it is important to study theoretically the parameters and efficiency of a hydro turbine. In that, the construction of the hydro turbine is a complex, its assembly is a very large-scale work. And so that, for a large-scale work to be correct and effective, it is important to preliminary study and make a conclusion. The accuracy of the numerical method is high. Using the mathematical model of a hydro turbine, it is possible to obtain an experimental and accurate model of a hydro turbine. If one of the parameters is erroneous in the experiment, it is difficult to change, it is necessary to change many settings, and it is easy to change in the simulation program and can be replaced by any parameter. We can analyze the increased process that passes. Without creating an experimental device, you can get the exact result in a computer program.

The hydro turbine is displayed in the COMSOL Multiphysics application package. The COMSOL Multiphysics application package examines the change in velocity and distribution of pressure of water through the guide vanes and the turbine blades [7]. The optimal shape and attack angle on guide vane and hydro wheel blades of the hydro turbine was determined. By investigating, the optimal configurations of the hydro turbine blades with high energy efficiency were determined.

External construction of 3 dimension model of hydro turbine which was made by Comsol Multiphysics application package is shown in Fig. 1. Inlet and outlet tube`s length is $200 \mathrm{~cm}$ and diameter is $150 \mathrm{~cm}$.

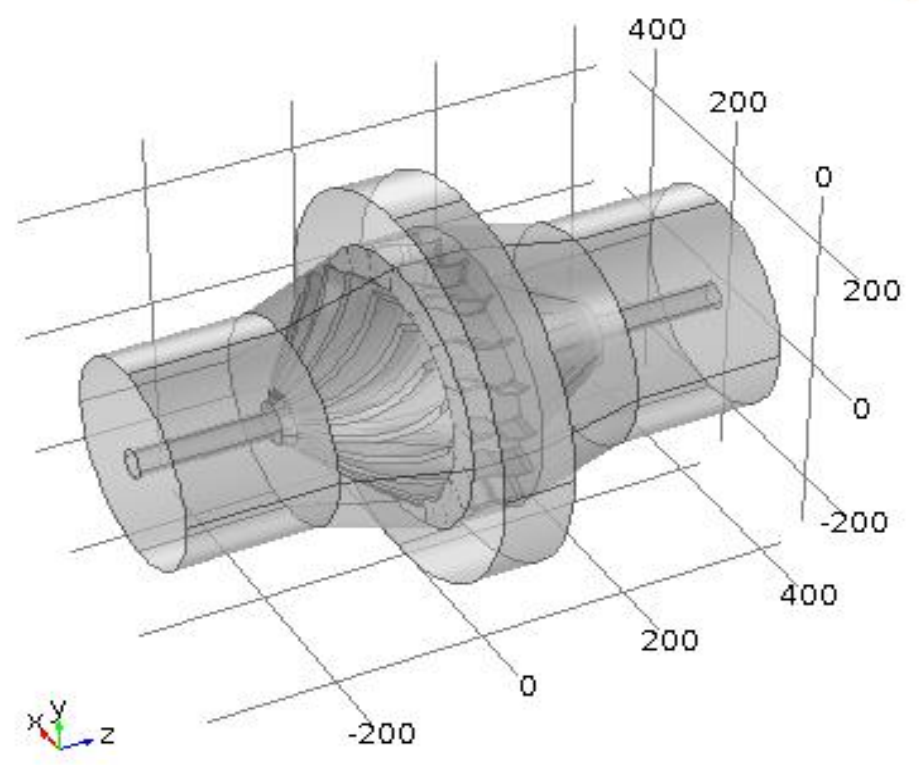

Figure 1. Hydro turbine model 
Inlet and outlet tube, shaft, guide vane and hydro wheel blades of hydro turbine is demonstrated. Guide vane and hydro wheel of the hydro turbine are shown in Fig. 2. Guide vane as cone form on the front part and blades which is located on cylinder part.

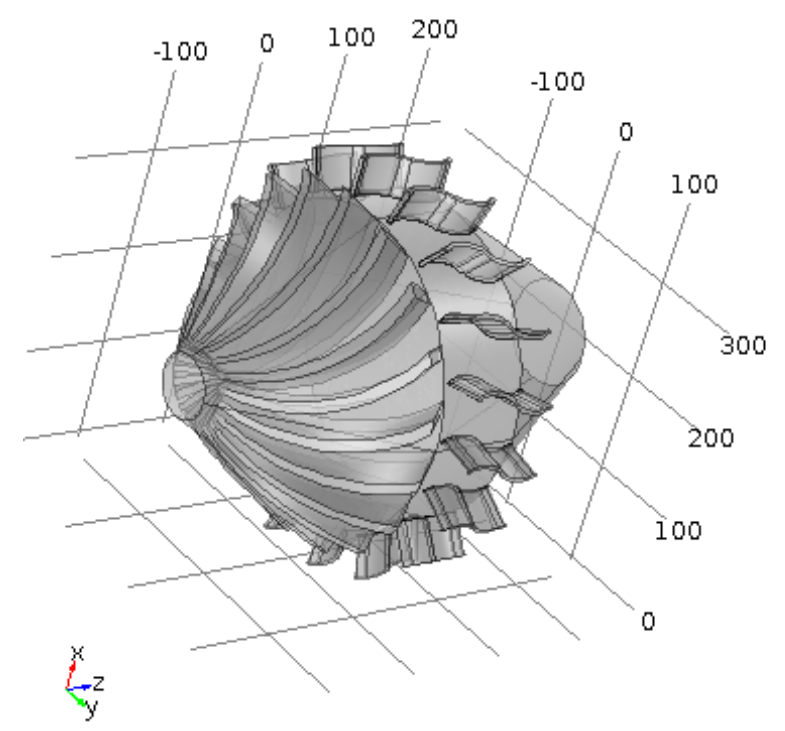

Figure 2. Hydro turbine guide vane and hydro wheel

The water with pressure enters through inlet tube, by rotating the rotor flows along the rotor and exit through the outlet tube. On the rotor`s outer shell located generator with winding which generates electricity.

To take more energy is needed to turn as more the hydro wheel. Therefore, there is a guide vane with the aim to regulate impact and direction of water flow to the hydro wheel blades. When water flow through hydro turbine passing through guide vane and hit blades with pressure, and they rotate $[8,9]$.

\section{Numerical experiment}

The energy efficiency of the hydro turbine is affected by the number, shape, location, and attack angle of the guide vane and blades [10]. Therefore, the results of the research of the attack angle on the guide vane and hydro wheel blades, angle between oncoming flow and chord of the blade, with the purpose of improving the energy efficiency of hydro turbine are presented.

Numerical calculation was performed by COMSOL Multiphysics application package. The results were obtained by changing the attack angle of the two blades of guide vane and two blades of hydro wheel for shaping the two dimensions. Three different angles were obtained to show the improving in energy efficiency and to compare. The distribution of velocity and pressure of water flow in COMSOL Multiphysics application packages during 10 seconds was analyzed with suggesting that the initial velocity $10 \mathrm{~m} / \mathrm{sec}$. The length of the guide vane blade is $160 \mathrm{~cm}$, width $4 \mathrm{~cm}$, the length of the hydro wheel blade is $80 \mathrm{~cm}$, width $4 \mathrm{~cm}$. 


\section{Mathematical model}

Distribution of water flow velocity and pressure was calculated with using Reynolds Averaged Navier Stokes (RANS) method.

For imcompressible fluid Navier-Stokes equations consists of motion and continuity equations [11]:

$$
\begin{aligned}
& \rho \frac{\partial u}{\partial t}+\rho(u \cdot \nabla) u=\nabla \cdot\left[-p I+\left(\mu+\mu_{T}\right)\left(\nabla u+(\nabla u)^{T}\right)\right]+F \\
& \rho \nabla \cdot(u)=0
\end{aligned}
$$

Task was calculated in Turbulent Flow, k- $\omega$ interface of COMSOL Multiphysics. It gives better results for considering internal flows and it takes into account wall functions.

Boundary conditions of the chosen blades in two dimension is shown in Fig.3.

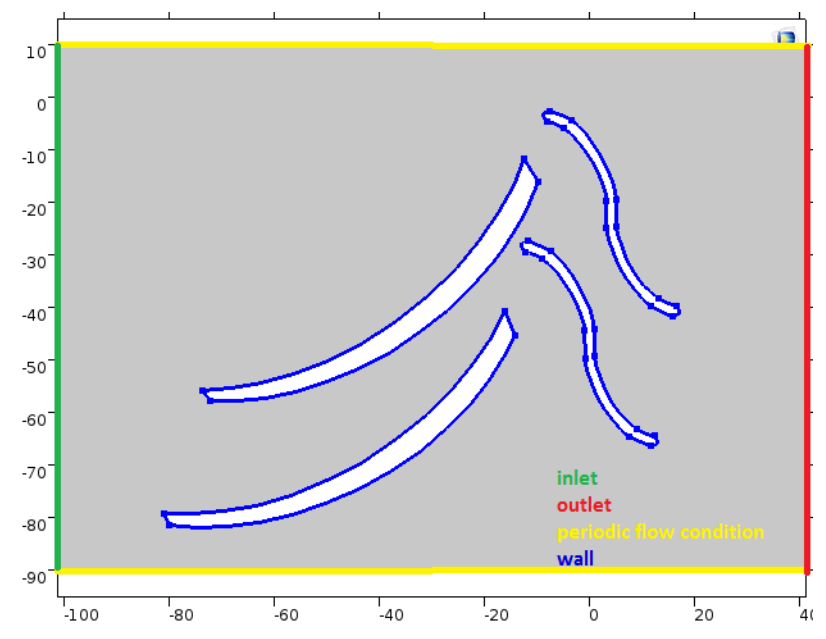

Figure 3. Boundary conditions

Inlet: $u=-U_{0} n, U_{r e f}=U_{0}, k=\frac{3}{2}\left(U_{r e f} / T\right)^{2}, \omega=\frac{k^{1 / 2}}{\left(\beta_{0}^{*}\right)^{1 / 4} L_{T}}$

Outlet: $\left[-p I+\left(\mu+\mu_{T}\right)\left(\nabla u+(\nabla u)^{T}\right)\right] n=-\hat{p}_{0} n,-\hat{p}_{0} \leq p_{0}, \nabla k \cdot n=0, \nabla \omega \cdot n=0$

Wall: $\left.u \cdot n=0,\left(\mu+\mu_{T}\right)\left(\nabla u+(\nabla u)^{T}\right)\right] n=-\rho \frac{u_{\tau}}{\delta_{w}^{+}} u_{\tan g}$ $u_{\text {tang }}=u-(u \cdot n) n, \nabla k \cdot n=0, \omega=\rho \frac{k}{k_{v} \delta_{w}^{+} \mu}$

Periodic flow condition: $\quad u_{\text {source }}=u_{\text {dest }}, p_{\text {source }}=p_{\text {dest }}, k_{\text {source }}=k_{\text {dest }}, \omega_{\text {source }}=\omega_{\text {dest }}$ Mesh allocation is shown in Fig.4. 


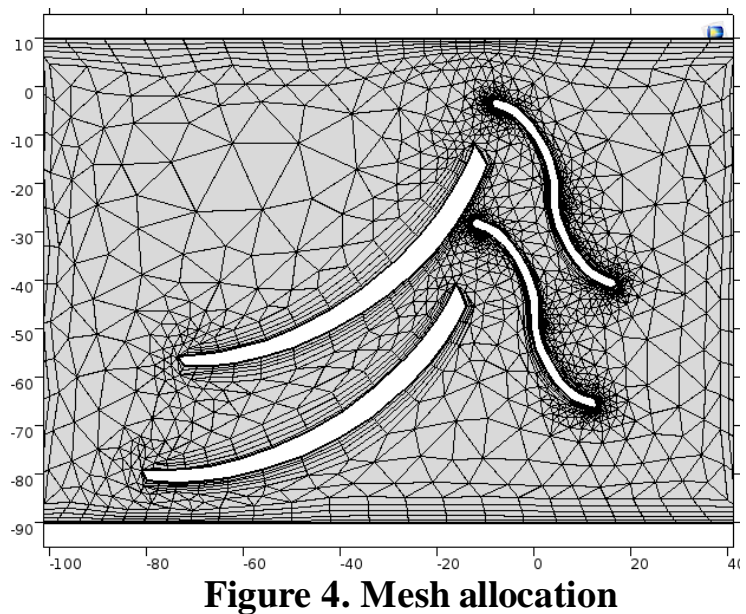

\section{Defining efficiency attack angle of blades}

Scheme of attack angle of the guide vane blade and attack angle of the hydro wheel blade is illustrated in Fig.5.

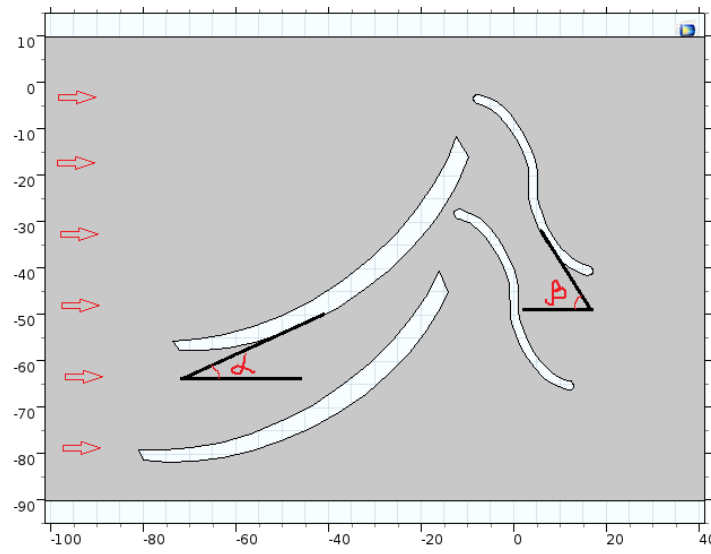

Figure 5. Attack angle

Firstly, guide vane blade`s attack angle $0^{\circ}$ and hydro wheel blade`s attack angle $0^{\circ}$ are obtained. For this case distribution of velocity and pressure are shown in Fig.6.

a.

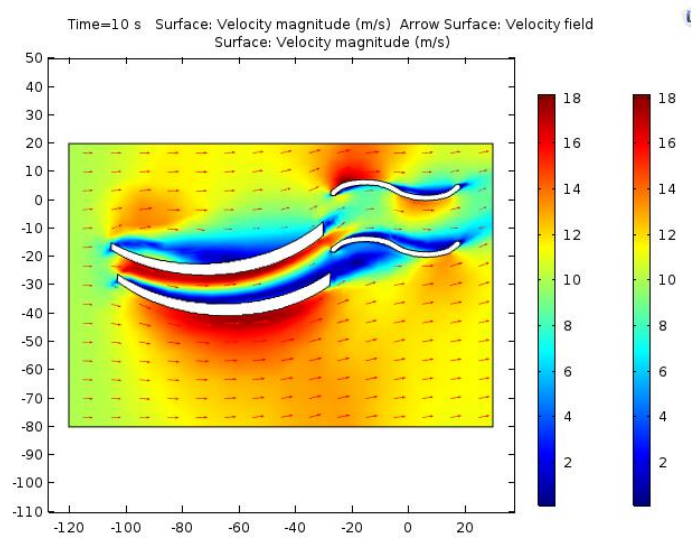

b.

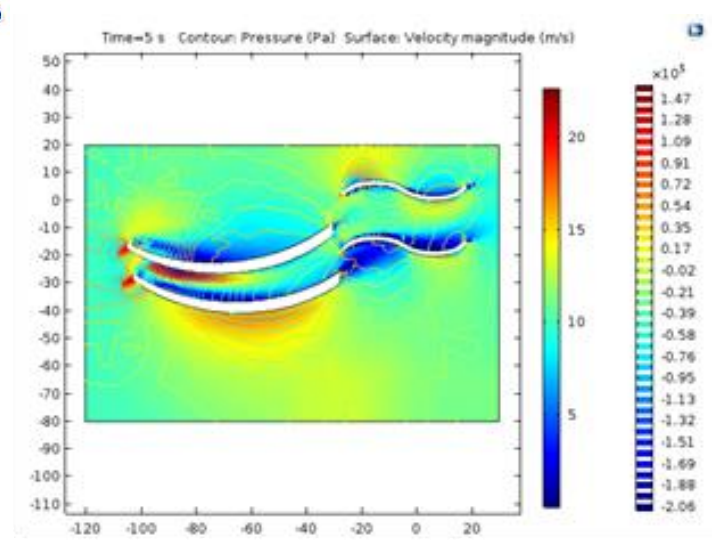

Figure 6. Guide vane attack angle $0^{\circ}$ and blade`s attack angle $0^{\circ}$ : a. distribution of velocity, b. distribution of pressure 
Maximum value of velocity is reached to $18 \mathrm{~m} / \mathrm{s}$ and maximum values of pressure is reached to $152 \mathrm{kPa}$.

Then results of turning guide vane to $30^{\circ}$ and blade to $60^{\circ}$ are demonstrated in Fig. 7 .

a.

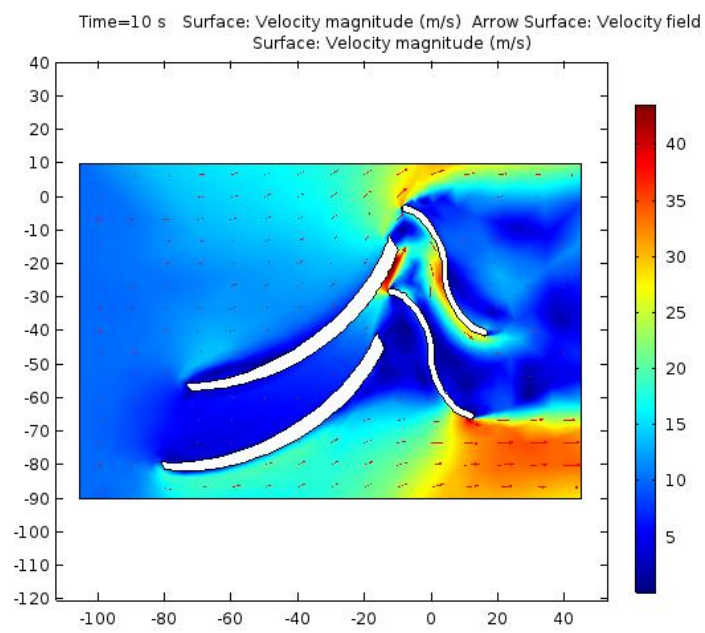

b.

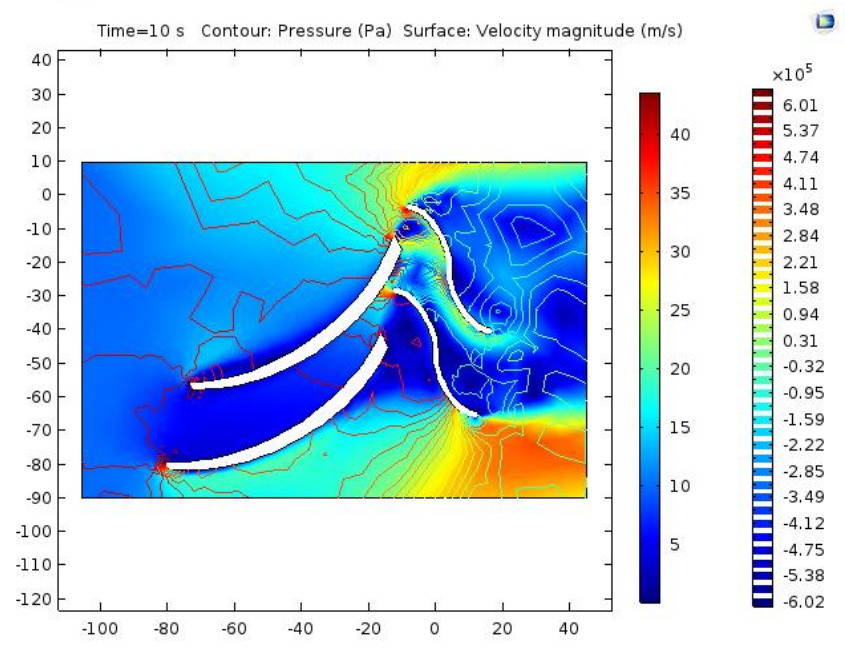

Figure 7. Guide vane`s attack angle $30^{\circ}$ and blade`s attack angle $60^{\circ}$ : a. distribution of velocity, $b$. distribution of pressure

In this case the maximum value of velocity is reached to $40 \mathrm{~m} / \mathrm{s}$ and maximum value of pressure is reached to $601 \mathrm{kPa}$. Comparing with previous results is observed that this version is more efficiently. So we can see that the attack angle has affect.

The process of distribution of velocity and pressure of the next version is showed in Fig. 8 .

a.

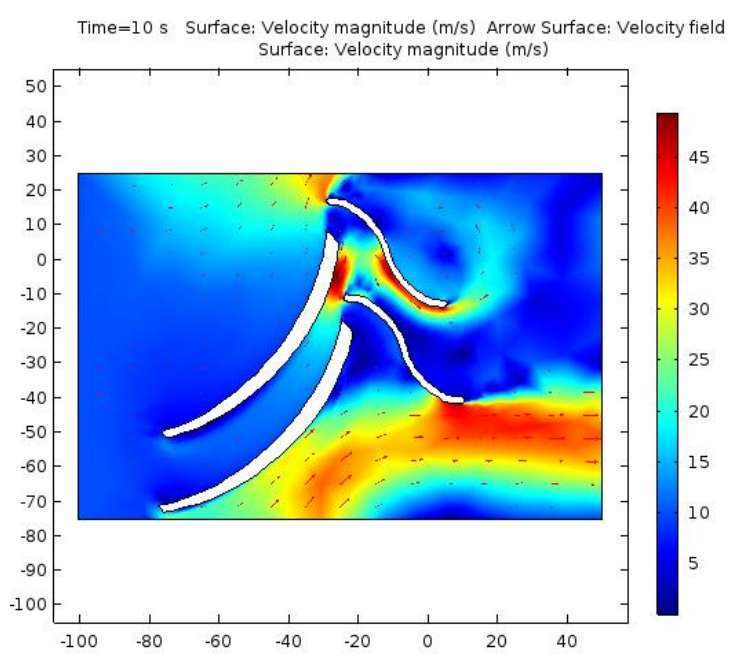

b.

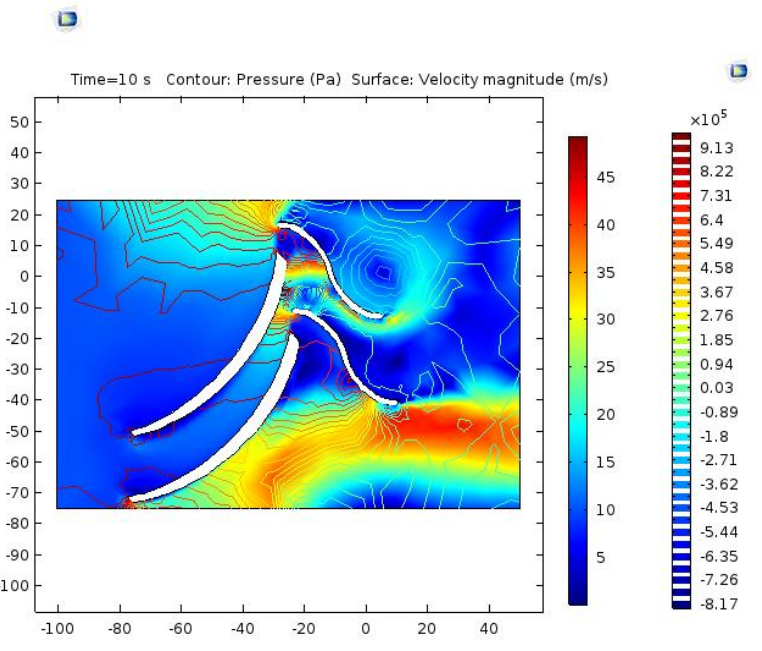

Figure 8. Guide vane`s attack angle $45^{\circ}$ and blade`s attack angle $45^{\circ}$ : a. distribution of velocity, $b$. distribution of pressure

There maximum value of velocity is reached to $45 \mathrm{~m} / \mathrm{s}$ and maximum value of pressure is reached to $913 \mathrm{kPa}$. 
Guide vane attack angle $50^{\circ}$ and blades attack angle $40^{\circ}$ are selected as the next version and results of distribution are shown in Fig.9.

a.

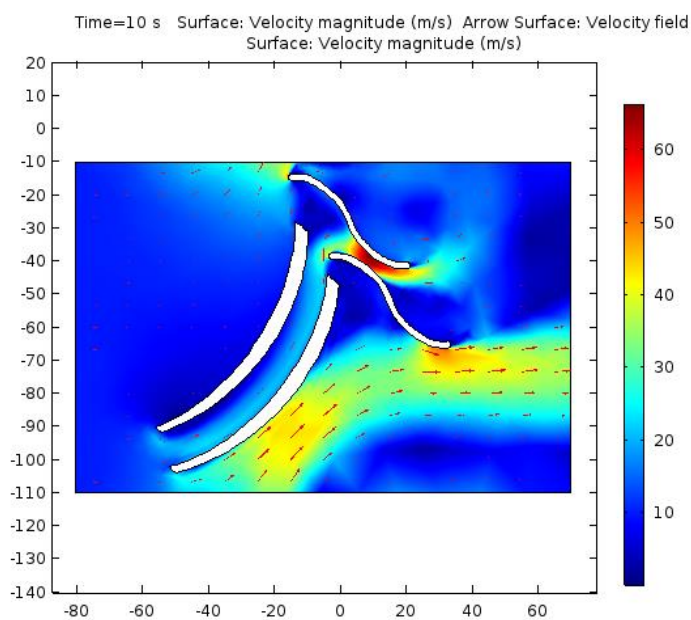

b.

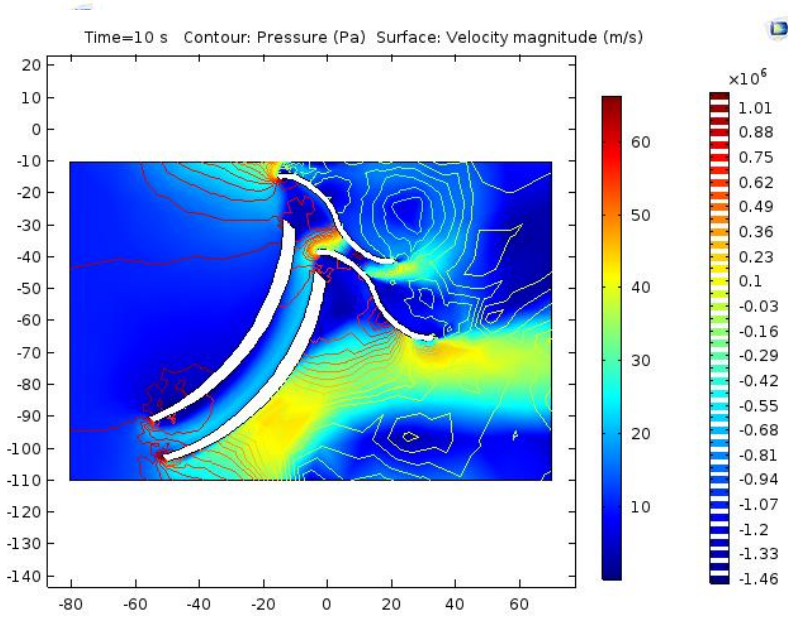

Figure 9. Guide vane`s attack angle $50^{\circ}$ and blade`s attack angle $40^{\circ}$ : a. distribution of velocity, $b$. distribution of pressure

There maximum value of velocity reached to $60 \mathrm{~m} / \mathrm{s}$ and maximum value of pressure are reached to $1010 \mathrm{kPa}$.

Results of numerical experiment by Comsol Multiphysics of the changing of velocity and pressure distribution of flow with changing attack angle of the blades are shown in Tab.1.

Table 1. Velocity and pressure changing with changing attack angle

\begin{tabular}{|c|c|c|c|c|}
\hline Name & $\begin{array}{c}\text { Attack angle of } \\
\text { guide vane, }^{\circ}\end{array}$ & $\begin{array}{c}\text { Attack angle } \\
\text { of blades, }\end{array}$ & $\begin{array}{c}\text { Maximum value } \\
\text { of velocity of } \\
\text { flow, } \mathrm{m} / \mathrm{s}\end{array}$ & $\begin{array}{c}\text { Maximum value } \\
\text { of pressure of } \\
\text { flow, } \mathrm{kPa}\end{array}$ \\
\hline 1 & 30 & 60 & 40 & 601 \\
\hline 2 & 45 & 45 & 45 & 913 \\
\hline 3 & 50 & 40 & 60 & 1010 \\
\hline
\end{tabular}

In last version when guide vane`s attack angle $50^{\circ}$ and blade `s attack angle $40^{\circ}$ maximum value of velocity and pressure are reached. Water flow hits blade with stronger pressure, rotates it and flows through turbine with higher velocity, that is concluded that efficiency is improved, therefore this version is choosen as the most optimal.

\section{Conclusions}

The effective version of hydro wheel blades of direct flow hydro turbine was determined. Research with the aim of improving efficiency of low head hydro turbine was performed. Three various locations of the blades with changing attack angle were investigated by Comsol Multiphysics. Based on the results of the research, it was determined the optimal configurations of the hydro wheel blades with 
effective efficiency. As optimal configuration was choosen guide vane with the attack angle 50 angle degrees and hydro wheel blade with the attack angle 40 angle degrees, where maximum value of velocity reached to $60 \mathrm{~m} / \mathrm{s}$ and maximum value of pressure reached to $1010 \mathrm{kPa}$.

\section{References}

[1] Koshumbayev, M., and Yerzhan, A., The innovative design of free-flow hydraulic turbine small hpp, 2nd International conference on innovative trends in multidisplinary academic research, Istanbul, Turkey, 2015, pp.56-57.

[2] Turalina, D., and Bossinov, D., Theoretical and experimental investigations to define optimal parameters of straight-flow turbine for non-dam hydro power station, Bulletin KazNU (Series Mathematics, Mechanics, Informatics), 84 (2015), pp. 124-131.

[3] Koshumbayev, M., Koshumbayev, A., Kvasov P., and Yerzhan, A., Straight-Flow hydro turbine for small rivers. 3rd International conference on innovative trends in multidisplinary academic research, Istanbul, Turkey, 2016, pp.47.

[4] Koshumbayev, M., and Kvasov P., New design low-pressure hydro-turbines for small hydro power station, The bulletin of the national academy of sciences of the republic of Kazakhstan, 359 (2016), pp. 69-74.

[5] Bossinov, D., and Koshumbayev, M., Innovative patent «Hydraulic unit». № 31166 (2016).

[6] Yerzhan, A., and Koshumbayev, M., Issledovanie gidroturbiny dlya povysheniya ehffektivnoj raboty maloj GEHS. Vsemirnyj Kongres inzhenerov i uchenyh «Energiya budushchego innovacionnye scenarii i metody ih realizacii» WSEC-2017, Astana, 2017, pp.177-179.

[7] COMSOL Multiphysics User’s Guide, May (2012), 1292 p.

[8] Bystritskiy, G., Gasangadzhiyev G., and Kozhichenkov V., Obshchaya energetika (Proizvodstvo teplovoy i elektricheskoy energii) Uchebnik, Knorus, Moscow, Russian, 2014, 410 p.

[9] Stesina, S., Gidravlika, gidromashini i gidropnevmoprivod: ycheb. posobie dlya vyzov. Akademiya, Moscow, Russian, 2007, 336 p.

[10] Bashta, T., Rydnev S., and Nekrasov B., Gidravlika, gidromashini i gidroprivodi: Ycheb. dlya vyzov. Alyans, Moscow, Russian, 2010, 423 p.

[11] Loytsyanskii, L., Fluid Mechanics. $6^{\text {th }}$ Edition. Science, Moscow, Russian, 1987, 840 p. 